\title{
Influence of RHA on Engineering Properties of Medium Plastic Clay
}

\author{
Nabeel Liaqat ${ }^{1}$ \\ (Author) \\ Lecturer: Civil Engineering Department \\ Swedish College of Engineering and Technology \\ Wah Cantt, Pakistan \\ Naeem Bashir Awan ${ }^{3}$ \\ (Co-Author) \\ Lecturer: Civil Engineering Department \\ HITECH University \\ Taxila, Pakistan \\ Mirza Farquleet Baig ${ }^{5}$ \\ (Co-Author) \\ Design Engineer: Kachhi Canal Consultant \\ Water and Power Development Authority \\ Lahore, Pakistan
}

\author{
Muhammad Farjad Sami ${ }^{2}$ \\ (Co-Author) \\ MS student: Civil Engineering Department \\ National University of Science and Technology \\ Islamabad, Pakistan \\ Mehtab Aalam ${ }^{4}$ \\ (Co-Author) \\ PhD Scholar: Institute of Mountain Hazards and \\ Environment \\ University of Chinese Academy of Science \\ Beijing, China
Sardar Faisal Abbas
(Co-Author) \\ MS student: Civil Engineering Department \\ University of Engineering and Technology \\ Taxila, Pakistan
}

\begin{abstract}
Subgrade acts as the foundation for road structures. The life and performance of roads structures greatly depends on the strength properties of subgrade soil. It is very common in Pakistan that engineers encountered with weak subgrade layer not suitable for construction of highways. The subgrade soils of Gujranwala are mostly low and medium plastic clays. These clays have high swell potential and low strength values. Clayey soils have degraded properties like low shear strength, low bearing capacity, high shrink and swell potential, low CBR and compressive strength value and high compressibility. These degraded properties are the common reason for most of the foundation failures. With the interaction of water clayey soils undergo volumetric change. With the increase in population density and increased demand of infrastructural development avoiding clayey soils for future construction is not possible. Soil improvement techniques should be applied on such soils before construction. Engineering properties of the site should be improved by some economical mean. This study has been carried out to check the suitability of Rice Husk Ash for the improvement in characteristics of medium plastic clay. RHA is available in Pakistan at a very low cost and is also a waste material in Pakistan. When medium plastic clay was treated with RHA a significant amount decrease in swell potential of soil was noted. Improvement in CBR value of treated soil was more than six times to the CBR value of untreated soil. Unconfined compressive strength was increased significantly $A$ change in index properties of soil was also observed. Significant decrease in Plasticity index of soil was noted. After treatment of soil a decrease in Maximum Dry Density and increase in Optimum Moisture Content was observed.
\end{abstract}

Keywords-Plastic clays, Rice Husk Ash, Soil stabilization, Soil Improvement, Subgrade soil, Stabilization Technique

\section{INTRODUCTION}

Clayey soils have expansive nature therefore they take an important place among soils. Expansive soils are the soils which with the change of water content have tendency to undergo volumetric change. The percentage of expansive clayey minerals present in the soil is the cause of volumetric variation potential of the soil. Chlorite, bentonite, montmorillonite, nontronite, illite, vermiculite, semectite, beidellite, etc are the common clay minerals. Because of weak inter-particle bonding of fine soil particles this soil easily absorb moisture and expands.

The role of soil is very important in the life of super structure. Damage caused by soil expansion is more than double the combined damage caused by the natural hazards like flood, earthquakes, hurricanes and tornados (Jones and Holtz, 1973). Breaking up and cracking of building foundations, pavements, irrigation systems, sewer lines, channel linings, gas pipeline and sewer lines is the result of expansive nature of soil. Pressure on vertical faced retaining walls is also the result of soil expansion. Soil become unstable and loses its strength due to shrinkage and swelling which causes slope failures and various forms of foundation problems.

Arid and semi-arid regions of the world normally contain expansive soils. Low bearing capacity, low shear strength, high compressibility and high shrink and swell potential are some of the common downgraded properties of expansive soils, so for engineering development these soils are not suitable.

The method of treating the expansive soils to make them fit for construction of civil engineering structures is known as stabilization. Variety of stabilizers may be divided into three groups (Petry 2002): (a) by-product stabilizers (fly ash, quarry dust, phosphor-gypsum, slag etc.), (b) traditional stabilizers (lime, cement etc.) and (c) non-traditional stabilizers (sulfonated oils, polymer, enzymes, potassium compounds and 
ammonium chlorides etc.). A large space is required for the disposal of large quantities of industrial by products as fills on disposal sites adjacent to industries and it also create a lot of geo-environment problems. Various organizations and researchers made a number of attempts to use industrial by products in bulk at suitable places. One way of utilization of these byproducts is stabilization of expansive soil.

\section{OBJECTIVES}

Soil stabilization gives technically feasible and one of the most economical solutions to many geotechnical engineering problems related to expansive soils. Most of the solutions in geotechnical engineering are specific for a given site, thus a recommended treatment for a particular site may not be applicable at a different location. It is therefore necessary that detailed field and laboratory investigations must be carried out before recommending a specific stabilization technique. The aim of this study is to find out a economical and permanently feasible solution for the problems of soil by improving the durability and strength characteristics of medium plastic clay to required level.

The main objective of this research was improvement in strength properties of medium plastic clays and to check the suitability of Rice Husk Ash to be used as a stabilizer for medium plastic clays. Main focus of this research is that how much Rice Husk Ash will help to improve the engineering properties of medium plastic clay.

\section{LITERETURE REVIEW}

On reviewing of past studies and researches a considerable amount of research concerning stabilization of soil with additives such as cement, lime, lime- fly ash and salt are available in the literature. But soil stabilization with RHA is relatively new method. Some research works which are conducted on expansive soil stabilization using RHA confirm the suitability of this material for soil stabilization as an admixture with lime and cement [3]. Properties of RHA depend upon the type of combustion it undergoes, whether it is destructive combustion or have been partially burnt. Different factors effecting properties of RHA are temperature and duration, location of crop, rate of heating, and variety of crop, fineness and year of production of crop [4]. Research studies also indicated that RHA properties are dependent on climatic conditions and chemistry of soil. According to different researchers the difference in properties of RHA may also be due to fertilizers applied to the rice crop during the cultivation period [6]. The chemical composition of RHA obtained from different areas as reported by A Muthadi, (2007) shows the difference in the chemical composition of RHA. Color changes in RHA of various areas are due to the structural transformations of silica in the ash as well as completeness of combustion process [7]. White color ash indicates that carbon is completely oxidized; white color also indicates the large percentage of amorphous silica present in the ash [8].

Basha et al. (2005) studied the effect of RHA and cement on the stabilization of expansive soils. In this research recommendations were made that 10 to 15 percent of RHA is the optimum percentage for the stabilization of expansive soils, and foro the same soil 6 to 8 percent of cement content was recommended as optimum value [9].

\section{MATERIALS}

\section{A. Soil}

The soil under study is medium plastic clay. Medium plastic clay samples were collected from village Ballewala near Nandipur, Gujranwala. Oven dried soil was used throughout the research.

\section{B. Rice Husk Ash}

RHA was used as a stabilizing agent in the study. The RHA was obtained from the kiln of Punjab Oil Mills , Islamabad.

\section{MEHODOLOGY}

Material testing was carried out in three phases

Phase I: Properties of untreated soil

Phase II: Optimization of RHA content

Phase III: Properties of treated soil

\section{A. Phase I}

The first step in this research was to determine the properties of untreated soil and to establish the potential of soil for stabilization. Following tests were performed in this phase

1. Grain size distribution

2. Compaction characteristics of soil

3. CBR and Swell Potential

\section{B. Phase II}

In this phase Modified proctor test and Unconfined Compressive Strength Test was performed on four different dosages of RHA. Four different dosages of RHA were 2, 4, 8 and 12 percent by weight of soil.

\section{Phase III}

In this phase Unconfined Compressive Strength Test and CBR and swell potential of soil was determined on optimized dosage. Only soaked CBR and one dimensional swelling was determined.

\section{RESULTS AND DISCUSSIONS}

\section{A. Grain Size Distribution}

The grain size distribution of medium plastic clay sample was determined by using wash sieve method following ASTM D 1140. The soil was pulverized and washed over sieve no 200. A $350 \mathrm{gm}$ of sample was taken and washed, 91 percent of soil sample passed through the sieve no 200.

Percentage of silt and clay present in sample of medium plastic clay was determined by performing hydrometer analysis. To perform this test ASTM ASTM D 7928-16 was followed. The hydrometer analysis showed that soil sample of medium plastic clay contains 55 percent of silt and 34 percent of clay. Results are shown in figure 1. 


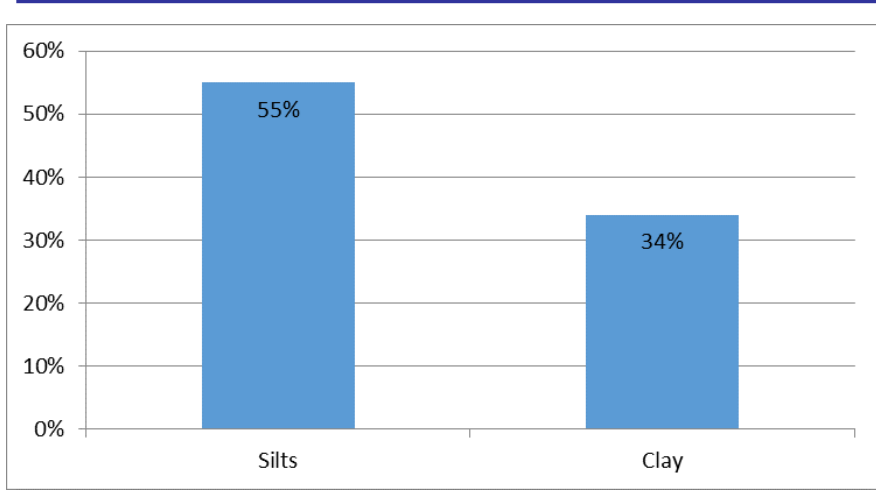

Fig. 1: Hydrometer analysis results

\section{B. Atterberg Limits of Soil}

Casagrande apparatus was used to obtain the liquid limit of soil. The value of liquid limit of medium plastic clay obtained from this test was 48 percent.

Plastic limit of medium plastic clay was determined by making threads of $1 / 8$ " thickness and its obtained was 24 percent.

Plasticity index of medium plastic clay was 24. Medium plastic clay was classified as CL as per USCS system and A6-7 as per AASHTO classification system.

The plasticity chart of medium plastic clay is shown in fig 2 .

Plasticity chart

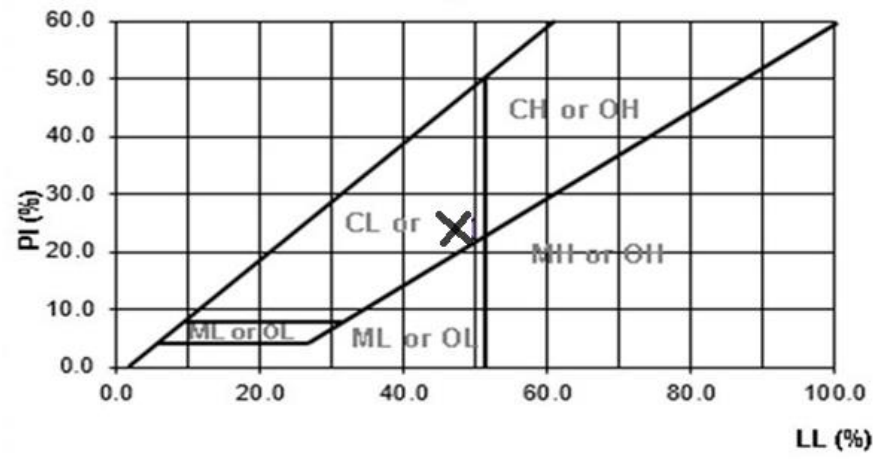

Fig. 2: USCS Classification chart

\section{Compaction Characteristics of Soil}

Compaction characteristics of medium plastic clays were determined by performing modified proctor test. MDD and OMC of medium plastic clay were determined as $1.94 \mathrm{~g} / \mathrm{cm} 3$ and 13.08 percent respectively. Results are shown in fig 3.

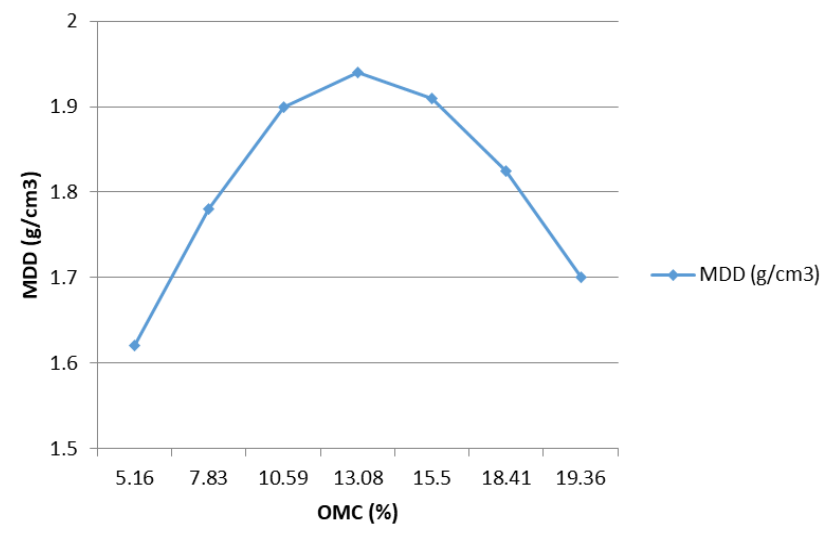

Fig. 3: Compaction characteristics of medium plastic clay

\section{Unconfined Compressive Strength Test with out}

\section{Trearment}

Unconfined Compressive Strength test's samples were made by using MDD and OMC values obtained from compaction characteristics test.

Unconfined compressive strength of medium plastic clay for unsoaked condition obtained was 218.29 psi. When soil sample was subjected to capillary soak for 48 hours its unconfined compressive strength reduced to $24.96 \mathrm{psi}$, the loss in strength due to soaking was almost $88 \%$.

E. Moisture Density Relationship at different RHA Contents

Moisture density relation was established for various RHA contents. Four tests were performed by adding 2, 4, 6 and 8 percent of RHA by weight of soil. Modified proctor test was used to determine the OMC and MDD for each sample.

The OMC increases with the addition of RHA and became maximum at 6 percent of RHA. And MDD decreases with the addition of RHA and is minimum at 6 percent RHA. Relation of Maximum Dry Density at different RHA contents is shown in fig 4 and relation of Optimum Moisture Content with different RHA content is shown in fig 5.

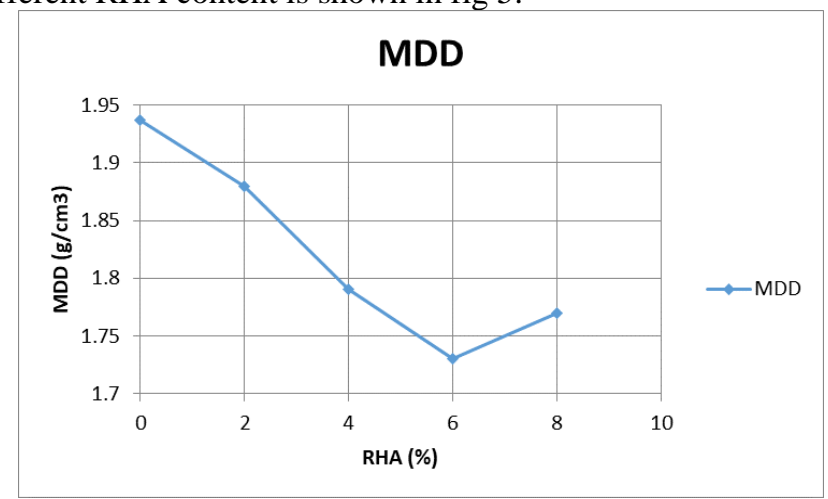

Fig. 4: Density relationship for different RHA contents

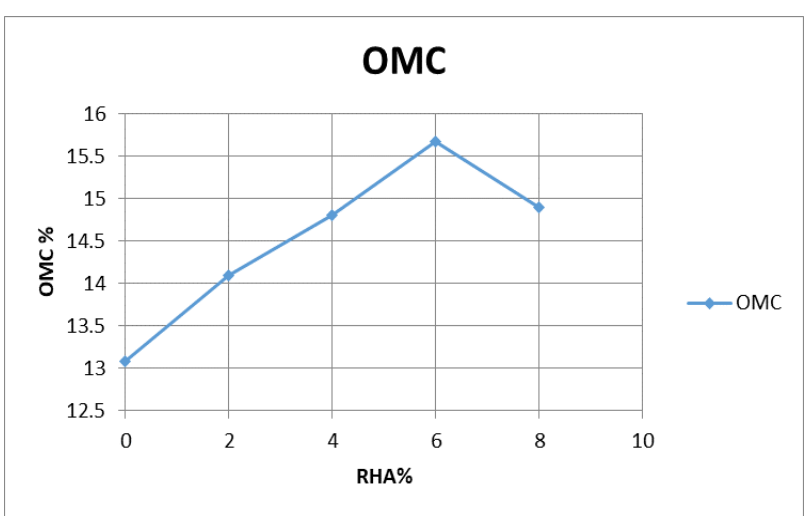

Fig. 5: OMC relationship for different RHA contents

\section{F. Calafornia Bearing Ratio and Swell Potential at different} RHA Contents

California Bearing Ratio and one-dimensional swell potential of treated and untreated soil was determined. This stage of testing also done in four phases, in first stage $2 \%$ of RHA was added, in second stage $4 \%$ of RHA was added to soil sample and in third stage $6 \%$ RHA were used in forth stage $8 \%$ RHA was used. Test results indicate that significant improvement was observed in $\mathrm{CBR}$ and one-dimensional swell. 
Table 1: CBR and Swell Potential at different RHA Contents

\begin{tabular}{|c|c|c|}
\hline RHA \% & CBR \% & Swell Potential \\
\hline 2 & 7.9 & 3.4 \\
\hline 4 & 10.6 & 2.6 \\
\hline 6 & 14.7 & 2.07 \\
\hline 8 & 13.3 & 2.5 \\
\hline
\end{tabular}

The highest value of CBR was obtained at 6 percent of RHA. So $6 \%$ RHA is optimum value of RHA. And best feasible value for treatment is 6 percent of RHA.

\section{G. Unconfined Compressive Strength Test Different RHA \\ Contents}

The samples were fabricated at 2, 4, 6 and 8 percent of RHA content at MDD and OMC obtained from modified proctor test. Two samples were prepared for each percentage and were kept in air tight plastic bags for 7 days at $30^{\circ} \mathrm{C}$ and after 7 days samples were tested.

At $6 \%$ RHA UCS value is maximum and is 440.12 psi. The results of UCS at different RHA contents are shown in fig 6.

\section{UCS}

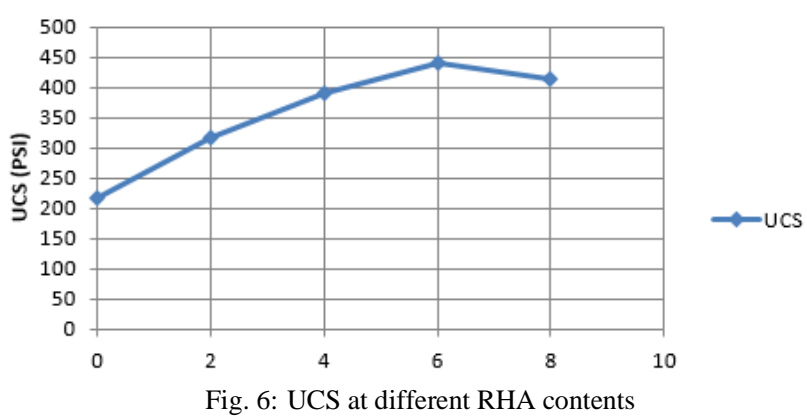

H. CONCLUSION

- It was noted that by addition of RHA MDD of soil decreases. The decrease in MDD was due to the flocculation of soil particles. Due to flocculation process soil particles become coarser and due to increase in size of particles MDD decreases. OMC of medium plastic clay increased significantly because of reaction between soil and admixtures. When RHA is added to soil and water is added exothermic reaction occurs and due to this more water is required for the stabilization process.

- The California Bearing Ratio was improved almost 5 times in treated form than in untreated form. One dimensional swell potential was reduced to $0.85 \%$. The nature of soil was converted from high to low swelling soil in treated form. A sufficient improvement in California bearing ratio and one-dimensional swell potential was observed with the addition of RHA.

- Unconfined compressive strength test was performed to both treated and untreated soil sample. And it was also performed for both soaked and unsoaked conditions. A significant improvement in unconfined compressive strength was noted. This improvement in unconfined compressive strength is associated with the pozzolanic reaction between soil RHA.

\section{ACKNOWLEDGEMENT}

We are thankful to Geotech lab of National University of Science and Technology for giving us equipment and space to complete our experimental work.

\section{REFERENCES}

[1] Gidley JS, Sack WS. Environmental aspects of waste utilization in construction. J Environ Eng ASCE 1984;110(6):1117-33.

[2] Basha, E. A., Hashim, R., Mahmud, H. B., \& Muntohar, A. S (2005). Stabilization of residual soil with rice husk ash and cement. Construction and Building Materials, 19(6), 448-453.

[3] Yin, C. Y., Mahmud, H. B., \& Shaaban, M. G. (2006). Stabilization/solidification of lead-contaminated soil using cement and rice husk ash. Journal of hazardous materials, 137(3), 17581764.

[4] Ali, F. H., Adnan, A., \& Choy, C. K. (1992). Geotechnical properties of a chemically stabilized soil from Malaysia with rice husk ash as an additive. Geotechnical and Geological Engineering, 10(2), 117-134.

[5] Sabat, A. K., \& Nanda, R. P. (2011). Effect of marble dust on strength and durability of Rice husk ash stabilised expansive soil. International Journal of Civil and Structural Engineering, 1(4), 939-948.

[6] Rahman, M. A. (1987). Effects of cement-rice husk ash mixtures on geotechnical properties of lateritic soils. Soils and Foundations, 27(2), 61-65

[7] Muntohar, A.S., 1999a, Effect of Lime and Rice Husk Ash on the Behavior of Soft Clay,

[8] Regional Seminar at Islamic University of Indonesia Sept. 4th 1999. Yogyakarta, Indonesia.

[9] Basha, E. A., Hashim, R., Mahmud, H. B., \& Muntohar, A. S. (2005). Stabilization of residual soil with rice husk ash and cement. Construction and Building Materials, 19(6), 448-453.

[10] Brooks, R. M. (2009). Soil stabilization with fly ash and rice husk ash. International Journal of Research and Reviews in Applied Sciences, 1(3), 209-217.

[11] Alhassan, M. (2008). Potentials of rice husk ash for soil stabilization. Assumption university journal of technology, 11(4), 246-250.

[12] Muntohar, A.S., 1999b, Behaviour of Engineering Properties on the Clay Blended with LRHA(Lime Rice Husk Ash), Research Report for Grant 1999 Muhammadiyah University of Yogyakarta, Indonesia. 